\title{
TECHNOLOGIA KRZEMIENIARSKA W PERSPEKTYWIE FILOZOFII TECHNIKI
}

\section{PREHISTORIC FLINT WORKING IN PERSPECTIVE OF PHILOSOPHY OF TECHNOLOGY}

\author{
Jakub Mugaj \\ Instytut Archeologii i Etnologii PAN \\ Ośrodek Studiów Pradziejowych i Średniowiecznych \\ ul. Rubież 46, 61-612 Poznań, Polska \\ j_mugaj@o2.pl
}

\begin{abstract}
The paper present non-instrumentalist view of technology derived by the work of M. Heidegger, G. Agamben and H. Arendt. This non-utilitarian aspect of technology is used to explain the social meaning of flint working in prehistory. The changes of flint technology related with so-called 'tool-technological revolution' observed in Neolithic indicate radical shift in social significance of technology. During this period the dichotomous division of work and labor (described by H. Arendt) appear.
\end{abstract}

KEY WORDS: flint technology, philosophy of technology, M. Heidegger, G. Agamben, H. Arendt

Studia nad technologią stanowią jedną z kluczowych sfer badań archeologicznych, a nawet szerzej - humanistycznych. O znaczeniu technologii świadczy to, że jedną $\mathrm{z}$ powszechnie funkcjonujących $\mathrm{w}$ dyskursie publicznym definicji człowieka jest ta autorstwa Benjamina Franklina, która opisuje człowieka jako istotę produkującą narzędzia - wytwarzanie narzędzi i posługiwanie się nimi ma świadczyć o naszym człowieczeństwie. Archeologia krzemieniarstwa jest w szczególny sposób związana ze studiami technologii. Materiał krzemienny, który jest podstawą, a nierzadko jedynym źródłem do konstruowania interpretacji o przeszłości, jest skutkiem czynności wytwarzania, produkowania, a więc czynności stricte technologicznych. 
Zanim podejmiemy rozważania dotyczące technologii, wyjaśnienia wymaga terminologia używana w niniejszym tekście. Istnieją dwa pojęcia związane z wytwarzaniem narzędzi: technika i technologia. Zakres znaczeniowy obu pojęć jest różny, jednak w dyskursie naukowym ta różnica jest często zacierana, a nawet ich sens jest odwracany. Chaos pojęciowy znajduje odzwierciedlenie w stosowaniu pojęcia „technika” w dyscyplinach filozoficznych czy naukach społecznych oraz powszechności używania w naukach ścisłych i potocznym języku terminu „technologia”. Również w archeologii krzemieniarstwa dominującym pojęciem jest technologia, zaś technika ma bardzo wąski, szczegółowy desygnat - oznacza metodę odbicia półsurowca. Bałagan terminologiczny pogłębia brak jasnej definicji techniki - we Wprowadzeniu do filozofii techniki Val Dusek rozróżnia trzy sposoby definiowania techniki: jako sprzęt, jako zbiór zasad oraz jako system (Dusek, 2011, s. 40-41). Pierwsza definicja łączy technikę z narzędziem - środkiem techniki. Druga opisuje technikę jako zbiór reguł wykonywania czynności - „schemat relacji pomiędzy środkiem a celem" (Dusek, 2011, s. 41). Ujęcie technologii jako systemu jest najszerszą definicją umieszczającą środki, cele, reguły w społecznym kontekście. W poniższym tekście używać będziemy zamiennie terminów technologia i technika (w zależności, czy będziemy poruszać się w obrębie analizy archeologicznej, czy filozoficznej) w tym samym ogólnym, szerokim kontekstualnym znaczeniu - pojęcia te obejmować będą kategorię wytwórczości, a więc przede wszystkim czynności wytwarzania oraz środków wykorzystywanych do tej czynności.

\section{INSTRUMENTALNY A ALTERNATYWNY OGLĄD TECHNOLOGII}

Problem ontologicznego statusu technologii w społecznościach pradziejowych, czym była technologia i jak była postrzegana, jest rzadko podejmowanym zagadnieniem w badaniach krzemieniarstwa. W dotychczasowych propozycjach interpretacyjnych i wyjaśnieniach przemian technologicznych dostrzec można jednak wyraźną dominację instrumentalnego oglądu technologii krzemieniarskiej. Widziana jest ona głównie w perspektywie jej użyteczności i funkcjonalności. Technologiczna zmiana jest opisywana w kategoriach innowacji, odpowiedzi na realną potrzebę wynikającą ze zmian zachodzących w innych sferach, przede wszystkim w sferze środowiskowej czy gospodarczej (np. mikrolityzacja w mezolicie jako proces adaptacyjny). W perspektywie długookresowej najpowszechniejszym wyjaśnieniem jest postęp. Przemiany technologii odbywają się samoistnie w imię rosnących potrzeb cywilizacyjnych człowieka. Najodpowiedniejsze innowacje zostają w procesie ogólnej ewolucji kulturowej przyswojone przez społeczeństwo. Kształt przemian i ich nieuchronność jest w tym sensie niejako oczywisty, wynikający z samej istoty procesu dziejowego. Przykładem takiego ewolucyjnego wyjaśnienia przemian technologicznych jest koncepcja „długości krawędzi pracującej” wskazująca na produktywność jako pod- 
stawową zmienną warunkującą rozwój technologiczny. Kolejne technologie krzemienne udoskonalały się przez zwiększenie długości krawędzi pracujących narzędzi pozyskanych z jednej bryły, i tak technologie otoczakowe, produkując pojedyncze narzędzia o krótkich krawędziach tnących, są najprostszą formą, bardziej rozwiniętym stadium są technologie rdzeniowe, zaś najdoskonalsze to wolumetryczne technologie mikrolityczne. Ten sposób rozumienia technologii związany jest $\mathrm{z}$ dominującymi $\mathrm{w}$ archeologii krzemieniarstwa paradygmatami badawczymi, a więc archeologii kulturowo-historycznej oraz procesualnej. Krzemieniarstwo funkcjonuje zatem w dwóch podstawowych dyskursach: adaptacyjnym i ewolucyjnym, których wspólnym podłożem jest instrumentalny, potoczny ogląd technologii (Standard View of Technology - Pfaffenberg, 1992, s. 494-496; Dobres, 2000, s. 12-46).

Celem artykułu jest przedstawienie alternatywnego sposobu rozumienia krzemiennej technologii pradziejowej jako kulturotwórczej, socjalizującej aktywności ludzkiej. Pytanie o przemianę technologiczną jest zatem pytaniem o zmianę społecznego kontekstu funkcjonowania technologii. Nie odnosimy się więc do konkretnych technologii w określonym miejscu i czasie - interesować nas będzie moment zasadniczego przełomu w krzemieniarstwie, która dzieli je na dwie fazy: starszą - krzemieniarstwa tradycyjnego związanego ze społecznościami łowiecko-zbierackimi górnego paleolitu, mezolitu i neolitycznych grup wczesnorolniczych oraz młodszą - tzw. krzemieniarstwa schyłkowego charakterystycznego dla późnego neolitu i epoki brązu.

Teza stawiana w niniejszym tekście brzmi: technologia (krzemienna) w pradziejach miała odmienny charakter niż technologia starożytna i nowożytna. Stanowiła całkowicie odrębne zjawisko społeczne, a przemiany technologii w okresie tzw. rewolucji technologiczno-narzędziowej związane są ze zmianą społecznego funkcjonowania krzemieniarstwa. Używanie współczesnych kategorii do opisu owego zjawiska jest zatem nieuzasadnione. Przedstawiona alternatywna koncepcja technologii pradziejowej odwołuje się do tez zawartych w filozofii Martina Heideggera, Giorgio Agambena oraz Hannah Arendt. Każdy z tych filozofów przedstawia nieinstrumentalne podejście do zagadnienia techniki i wytwarzania. Ukazują oni równocześnie przemiany pojęcia techniki w nowożytności, wskazując na stosunkowo młodą genealogię współczesnego rozumienia technologii. Zaprezentowana alternatywna koncepcja pradziejowej technologii stanowi uzupełnienie kontinuum przemian techniki, które wyłania się z filozofii Heideggera, Agambena i Arendt.

\section{HEIDEGGER - ONTOLOGIA RZECZY PRZECIWKO INSTRUMENTALIZACJI}

Jednym z najważniejszych współczesnych filozofów poruszających problem techniki, a jednocześnie krytykiem instrumentalnego podejścia do technologii był M. Heidegger, który w swoim eseju „Pytanie o technikę” pisał, że „istota techniki 
wcale nie jest czymś technicznym" (Heidegger, 2002a, s. 7) ${ }^{1}$. Sens rzeczy i narzędzi kryje się nie w jej funkcji i użyteczności, taki ogląd jest powszechnym instrumentalnym rozumieniem techniki:

Każdy zna dwa poglądy, które odpowiadają na nasze pytanie. Jeden mówi: technika jest środkiem do celów. Drugi powiada: technika jest czynem człowieka. Obiegowe przedstawienie techniki, zgodnie z którym jest ona środkiem i ludzkim czynem, można zatem nazwać instrumentalnym i antropologicznym określeniem techniki (Heidegger, 2002a, s. 8).

Choć instrumentalności techniki i narzędzi nie da się zaprzeczyć, nie jest to cecha, która stanowi o istocie techniki.

Heidegger w definiowaniu techniki wraca do starożytnego, pierwotnego pojęcia techne, oznaczającego wytwarzanie, wykonywanie. Pojęcie to należało do szerszej kategorii poiesis. Techne było zatem czymś więcej niż rzemiosło, rękodzielnictwo było bliskie sztuce, bowiem miało pozapraktyczną wartość. Podobnie jak dla starożytnych, technika wedle Heideggera ma poniekąd wymiar poznawczy, jest odkrywaniem i ujawnianiem. Każda wytwórczość to przechodzenie ze skrytości w nieskrytość, wydobywaniem z natury. Według filozofa z Fryburga, zwłaszcza w jego późnych pracach, technika ma charakter procesualny - realizuje się nie tylko w rzeczy, ale w ciągłym procesie ,rzeczowienia”. Koncepcja techniki realizowana jest zatem podobnie jak projekt ontologii fundamentalnej poprzez przeniesienie punktu ciężkości z bytu na bycie, z rzeczy na rzeczowienie (Barański, 2008, s. 23). Pierwotnym zamiarem techniki jest samo wytworzenie, stawanie się przedmiotu, dopiero w następnej kolejności przedmiot zostaje użyty (Maliński, 2016, s. 171).

W nowoczesności technika staje się czymś innym, jej poprzedni, przednowoczesny sens zostaje zdominowany przez postrzeganie rzeczy jako zasób (Bestand). „Wszędzie dostawia się to, aby stało na miejscu, mianowicie stało po to, aby samo było dostawialne do dalszego dostawiania. Coś tak dostawionego ma własny stan (Stand). Nazywamy go zasobem (Bestand)" (Heidegger, 2002a, s. 21). Przedmioty istnieją w potencjalności ich przetworzenia, są zasobem energii lub kapitału do wykorzystania i kolejnego dostawiania, ustawiania. To zestawianie (Ge-stell), jak nazywa je Heidegger, jest dominującym sposobem istnienia techniki w świecie współczesnym (Olsen, 2013, s. 131). Zestaw jest traktowany przez autora Bycia i czasu jako zjawisko negatywne, powodujące zagubienie istoty techniki, a przez to istoty człowieka. W nowoczesnym świecie zapomnieniu uległ pozatechniczny sposób

\footnotetext{
${ }^{1}$ Warto zaznaczyć, że rozważamy w tym miejscu poglądy M. Heideggera z jego późnych prac, takich jak eseje „Pytanie o technikę” (2002a) czy „Budować, mieszkać , myśleć” (1974). Poglądy te stoją w pewnej sprzeczności z wcześniejszymi koncepcjami techniki, w których centralnym pojęciem definiującym rzecz jest jej „poręczność” (Heidegger, 1994). Przemiana filozofii Heideggera określana jest w literaturze jako „zwrot”, który dokonał się miedzy 1930 a 1936 rokiem (Hoły-Łuczaj, 2013, s. 95-97). Kluczowym przejściem po „zwrocie” było odejście od ontycznej w kierunku perspektywy ontologicznej.
} 
myślenia - instrumentalny ogląd rzeczy i ludzi stał się tak powszechny, że uważamy go za naturalny (Dusek, 2011, s. 87). Heidegger zagrożenie widzi w poszerzaniu kategorii zasobu również na innych ludzi (Kogge, 2010, s. 84), ,[...] ponieważ bycie jako istota bycia przesłało się w zestaw, a do istoty bycia należy istota człowieka [...]. W każdym razie do zwinięcia istoty techniki wykorzystywany jest człowiek" (Heidegger, 2002b, s. 51). Rozwiązaniem owego zagrożenia może być jedynie powrót do pojetycznego widzenia techniki (Kogge, 2010, s. 90).

\section{AGAMBEN - POIESIS A PRAXIS}

Heidegger powraca do starożytnego pojęcia techne i poiesis, próbując zaprezentować własne, nieinstrumentalne rozumienie techniki. Antyczne rozróżnienie na poiesis i praxis eksploruje również włoski filozof Giorgio Agamben ${ }^{2}$. Według niego współcześnie pojęcia te zostały rozmyte, a nawet odwrócono ich znaczenia. Podstawową bowiem różnicą było wytwarzanie przez poiesis czegoś ponad samą siebie. Cel tworzenia w wariancie poiesis wykraczał poza samą produkcję. Podążając tropem Heideggera, Agamben rozważa poiesis jako aktywność tworzenia, działanie powołujące do istnienia, wydobywanie prawdy (Agamben, 1999, s. 42). Praxis natomiast to działanie powiązane $\mathrm{z}$ wolą, polega na urzeczywistnieniu, wyprodukowaniu. Różnica między dwoma rodzajami działania polega na różnej lokalizacji jego granicy: „Poiesis posiada granicę poza sobą; oznacza to, że jest produktywna, stanowi źródłową zasadę czegoś różnego od siebie. Z kolei wola stanowiąca źródło praxis i osiągająca swoją pełnię w działaniu, pozostaje zamknięta we własnym kręgu" (Agamben, 1970, cyt. za: Mościcki, 2012, s. 47). Starożytny podział charakteru ludzkich czynności został z czasem zatarty - Agamben śledzi genealogię rozmycia obu pojęć od momentu ich translacji na myśl łacińską (Agamben, 1999, s. 43). W efekcie współcześnie nie rozróżniamy poiesis od praxis - działanie jako wydobywanie, odkrywanie prawdy zlało się z działaniem jako aktem woli (Mills, 2010, s. 339). Ponadto to praxis, zgodnie z marksowską definicją człowieka, stało się jego źródłową cechą. Choć Agamben skupia się na erozji pojęcia poiesis w kontekście dzieła sztuki - jego utowarowienia, rozumienia jako produktu, wyrazu woli twórcy (Mills, 2010, s. 341), proces ten odnosi się również do techniki (techne), która jeszcze wcześniej została całkowicie oddzielona od poiesis (Mościski, 2012, s. 50).

Agamben zgłębia zatem Heideggerowską koncepcję techniki, wskazując na pozapraktyczny wymiar aktywności wytwórczej. Jego rozróżnienie kategorii poiesis i praxis nawiązuje do innej fundamentalnej dla filozofii techniki pracy - Kondycji ludzkiej Hannah Arendt.

\footnotetext{
${ }^{2}$ Nie bez znaczenie jest fakt, że G. Agamben uczestniczył w wykładach Heideggera we wczesnych latach 60. Jego pierwsza praca L'uomo senza contenuto (1970) jest wyraźnie naznaczona myślą niemieckiego fenomenologa.
} 


\section{ARENDT - PRACA A WYTWARZANIE}

W Kondycji ludzkiej Hannah Arendt wskazuje na dwie sfery ludzkiego życia: vita activa oraz vita contemplativa. Pierwsza z nich odnosi się do każdej aktywności fizycznej - działania, natomiast druga do rozmyślania - aktywności mentalnej. Vita activa składa się z trzech głównych filarów: pracy, wytwarzania oraz działania. To rozróżnienie jest głównym tematem Kondycji ludzkiej i osią rozważań Arendt. Wyjaśnienie dychotomii pracy i wytwarzania jest w dużej mierze dyskusją z marksizmem. Zgodnie $\mathrm{z}$ marksowskim rozumieniem praca to proces przekształcania przyrody na użytek człowieka: „praca jest procesem zachodzącym między człowiekiem a przyrodą, procesem, w którym człowiek poprzez swoją działalność realizuje, reguluje i kontroluje wymianę materii z przyrodą" (Marks, 1951, s. 188). Każda praca, która osiąga swój cel w produkcie, jest pracą produkcyjną, zaś taka, która generuje dobra niematerialne, jest pracą nieprodukcyjną. To podstawowe rozróżnienie jest wspólne zarówno dla ekonomii klasycznej, jak i dla marksizmu. Podział ten, jak przyznaje Arendt ,zawiera fundamentalną różnicę między wytwarzaniem a pracą" (Arendt, 2010, s. 110). Każdy proces pracy w rozumieniu Arendt charakteryzuje się tym, że nie wytwarza żadnej trwałej rzeczy, efekty pracy są bowiem niemal natychmiast konsumowane. Ta nietrwałość efektów wysiłku włożonego w czynność pracy wynika z podstawowej jej funkcji, jaką jest zapewnienie biologicznej egzystencji człowieka - praca odpowiada na życiowe potrzeby człowieka. Ma zatem charakter ciągły, nieskończony i powtarzalny. Efekty pracy są automatycznie wykorzystywane w procesie życiowym.

Wytwarzanie jest formą aktywności, która kończy się wyprodukowaniem dobra materialnego, rzeczy. Rzeczy te są przedmiotami użytkowymi, służącymi budowaniu świata, stwarzaniu świata. Wytwarzanie jest zatem procesem uprzedmiotawiania świata (Arendt, 2010, s. 166).

Podstawowa różnica między dwoma sposobami działania człowieka (pracy i wytwarzania) wyraża się najlepiej w określeniach ,praca naszego ciała” i „dzieło naszych rąk". Dzieło jest pojedynczym trwałym, materialnym rezultatem, podczas gdy praca jest procesem, czynnością. Arendt zauważa, że ślady owego rozróżnienia pozostały w języku. Angielskie terminy oznaczające pracę to work i labor. Pierwsze z nich odnosi się do pracy jako dzieła - np. dzieło sztuki (art-work), zaś drugie do pracy jako czynności, np. prace Heraklesa (labors of Hercules). Wytwarzanie według Arendt jest siłą rzeczy czynnością zindywidualizowaną - musi odbywać się samodzielnie, a jedyną formą upublicznienia wytwarzania i wytworów jest rynek wymiany: ,homo faber, budowniczy świata i wytwórca rzeczy, może odkryć właściwą więź z innymi ludźmi, tylko wymieniając się z nimi swoimi wytworami, ponieważ same te produkty są wytwarzane w odosobnieniu" (Arendt, 2010, s. 189). Proces pracy przesunięty jest zatem w sferę prywatną, zaś w sferze publicznej, w obiegu społecznym funkcjonuje już gotowy produkt wytwarzania. 
Trzeci rodzaj aktywności - działanie - rozumiane jest przez Arendt jako aktywność publiczna, niemająca trwałych efektów w postaci dobra konsumpcyjnego oraz niewynikająca jedynie z potrzeb naturalnych. Jest formą działania politycznego, przy czym polityka rozumiana jest jako arystotelesowskie sprawy publiczne, społeczne. W działaniu dopiero uwidacznia się społeczny wymiar ludzkiej aktywności. Ani praca, ani wytwarzanie $\mathrm{w}$ indywidualnym wymiarze nie określają kondycji ludzkiej. Dopiero działanie jako forma bycia razem, interakcji, pozwala na pełne bycie człowieka. Wszystkie wymienione formy aktywności są zgodnie ze starożytną intuicją zhierarchizowane. Najniżej ceniona jest praca będącą zniewoleniem człowieka przez naturę. Praca upodabnia człowieka do zwierzęcia wiedzionego koniecznością przeżycia - animal laborans. Wytwarzanie jest natomiast domeną homo faber, który twórczo przetwarza naturę w urzeczowiony świat i konsumuje wyprodukowane przez siebie dobra. Najwyższa wartość przypisana jest działaniu i mowie jako uspołecznionej aktywności (Dusek, 2011, s. 144).

Trójpodział aktywności ludzkiej dokonany przez Arendt w Kondycji ludzkiej służy krytyce przemian społecznych, które zaistniały w nowoczesności. Według filozofki wyraźny rozdział działań ludzkich na pracę, wytwarzanie i działanie widoczny w starożytności został zaburzony. W nowoczesności działanie zostało zmarginalizowane przez rozszerzenie sfery prywatnej na dziedzinę publiczną, zaś automatyzacja i rozwój technologii przyczyniły się do zmiany charakteru wytwarzania, które zyskało cechy pracy (Arendt, 2010, s. 263). W nowoczesnych fabrykach produkcja przestała być domeną rzemieślników, ale stała się efektem powtarzalnych działań niewyspecjalizowanych robotników lub maszyn.

\section{PRZEMIANY TECHNOLOGII KRZEMIENIARSKIEJ}

W konsekwencji przyjęcia płaszczyzny teoriopoznawczej wyłaniającej się z filozofii techniki Heideggera, Agambena i Arendt należy na przemiany technologii krzemieniarskiej spojrzeć z innej perspektywy. Zarysowany przez tzw. rewolucję technologiczno-narzędziową (Schild, Królik, Mościbrodzka, 1977; Lech, 1982/1983) dychotomiczny podział na krzemieniarstwo starsze - „tradycyjne” oraz młodsze „późne/schyłkowe” ukazuje dwie fazy odmiennej społecznej percepcji technologii.

Rewolucja technologiczno-narzędziowa opisywana jest w literaturze jako swoisty przełom charakteryzujący się przede wszystkim ,,makrolityzacją narzędzi, zanikiem techniki wiórowej, wzrostem znaczenia techniki rdzeniowej, dwuściennością i powierzchniową obróbką narzędzi”" (Kopacz, Valde-Nowak, 1987, s. 79). Jak zaznaczają badacze, zmiany owe nie były rewolucją w ścisłym ujęciu tego słowa, nie miały bowiem cech nagłego, skokowego przełomu, lecz były raczej długotrwałym i niejednorodnym procesem (Kopacz, Valde-Nowak, 1987, s. 83). Krzemieniarstwo przed przełomem, charakterystyczne dla społeczności łowiecko-zbierackich i wcze- 
snorolniczych cechuje się niezwykłą jednolitością. Wystarczy wspomnieć o tak przejrzystych konceptach technologicznych, jak technologia magdaleńska (Połtowicz-Bobak, 2013, s. 228), janisławicka (Wąs, 2005, s. 229) czy społeczności wstęgowych (Kabaciński, 2010, s. 180), które są zwartym systemem homogennym zarówno w obrębie pojedynczych struktur osadniczych, jak i często w całym zasięgu występowania. W tym „tradycyjnym” modelu obróbka krzemienia opierała się na koncepcji rdzenia wolumetrycznego. Od właściwie przygotowanego rdzenia oddzielane były odłupki oraz wióry, które następnie kształtowano w odpowiednie formy narzędziowe. Formy te budowały spójny, bogaty zestaw narzędziowy, zasadniczo powtarzający się w poszczególnych inwentarzach. W zespołach krzemiennych tego okresu obróbka krzemienia funkcjonuje powszechnie w ramach jednolitego modelu.

Odmiennie wygląda krzemieniarstwo schyłkowe ${ }^{3}$. Obserwować można w tej fazie stopniowe wydzielanie się w obrębie systemu technologicznego modułu technologii wyspecjalizowanej. W źródłach archeologicznych zaznacza się ona $\mathrm{w}$ formie tzw. narzędzi konwencjonalnych (Kopacz, Valde-Nowak, 1987, s. 78) - wysokojakościowych produktów opracowanych retuszem powierzchniowym bifacjalnym, świadczących o dużych umiejętnościach wytwórców. Poza modułem wyspecjalizowanej wytwórczości narzędzi konwencjonalnych, system technologiczny charakteryzuje się maksymalnym uproszczeniem koncepcji i metod obróbki. Zanika technologia wiórowa - wyraźnie zaznacza się dominacja rdzeniowania odłupkowego oraz eksploatacji przy użyciu techniki łuszczniowej. Zarówno użyte techniki obróbki, jak i jakość lokalnych surowców krzemiennych wpływa na nieregularne, odłupkowookruchowe formy uzyskiwanego półsurowca. Struktura narzędziowa inwentarzy schyłkowych ulega silnej redukcji - występujące na stanowiskach narzędzia trudno zaklasyfikować do jasno wydzielonych typów - dominują narzędzia nietypologiczne (Kopacz, 2012, s. 40). Jak podkreślają autorzy, obróbka sprawia wrażenie ,przypadkowej i niedbałej" (Kabaciński, 2017, s. 461), zaś:

w żadnym z przemysłów krzemieniarskich wcześniejszych okresów pradziejów nie obserwujemy tak wielkiej dysproporcji ilościowej pomiędzy formami o określonych,

\footnotetext{
${ }^{3}$ W kontekście uwag dotyczących teoretycznego zaplecza badań materiałów krzemiennych późne krzemieniarstwo jawi się jako wyjątek, który wynika przede wszystkim ze specyfiki epoki: ilości i różnorodności źródeł pozakrzemiennych. Nacisk kładziony jest bowiem często na symboliczny, prestiżowy charakter wyrobów krzemiennych, które odgrywały rolę materialnego wskaźnika elitarności w rangowych społecznościach, strukturyzowały relacje władzy (Apel, 2001; Masojć, 2014). Podkreślana jest również rytualna funkcja obróbki krzemienia. Wedle owej koncepcji łupanie krzemienia nie miało realizować potrzeb gospodarczych, rzemieślniczych, ale było formą rites de passage, inicjacyjnych obrzędów socjalizujących (Masojć, 2014, s. 176). Interpretacja ta jest ważna dla niniejszych rozważań, ponieważ jest jak dotąd jedynym w studiach krzemieniarskich ujęciem technologii krzemieniarskiej w perspektywie samego działania, a nie efektu działania - wyrobu lub normatywnie ujętych sposobów tego działania.
} 
powtarzających się cechach (rdzeniami, półsurowcem, narzędziami typologicznymi) a masą przedmiotów bez wyraźnego kształtu, przeznaczenia, a nawet pochodzenia (często trudno określić, czy mamy do czynienia z odpadami, czy produktami zamierzonymi) (Kopacz, 2012, s. 41).

Możemy zatem mówić o wyraźnie dychotomicznym systemie technologicznym krzemieniarstwa schyłkowego (Van Gijn, 2010, s. 219; Wolski, 2013, s. 178), którego jeden moduł ulega uproszczeniu i swoistej pauperyzacji technologicznej, zaś drugi jest wysoko rozwiniętą technologią o najprawdopodobniej ekskluzywnym, elitarnym charakterze, a transmisja wiedzy o tej technologii odbywa się w ramach węższej grupy społecznej (Van Gijn, 2010, s. 223; Wolski, 2013, s. 190).

\section{DYSKUSJA}

W perspektywie długiego trwania rysują się zatem dwa okresy różniące się sposobem funkcjonowania krzemieniarstwa. Pierwszy okres to czas krzemieniarstwa jednolitego i trwałego. Wytwarzanie krzemieni było czynnością o charakterze codziennym, rutynowym. Transmisja wiedzy odbywała się wraz $\mathrm{z}$ wytwarzaniem, miała charakter socjalizujący. Cykliczna, powtarzalna obróbka krzemienia pozwalała na nieustanne reprodukowanie i utrzymywanie spójności społecznej i kulturowej. W fazie drugiej - późnego krzemieniarstwa - wytwórczość zaczyna funkcjonować w dwóch modułach: podomowym oraz wyspecjalizowanym. Pierwszy z nich zachowuje powszechny charakter krzemieniarstwa poprzedniej fazy, ale całkowicie traci jej kulturotwórczy wymiar. Drugi moduł z kolei staje się technologią ekskluzywną, krzemieniarstwo w tej formie nie jest już zrutynizowaną czynnością wykonywaną przez wszystkich. Przestaje także mieć znaczenie procesualny wymiar produkcji krzemieniarskiej - jej wartość realizuje się w produkcie o wysokiej jakości technicznej oraz symbolicznej - jeśli zatem zachowana jest kulturotwórcza funkcja krzemieniarstwa, to nie w samym wytwarzaniu, a w narzędziu. Tę dwumodułowość można przedstawić jako efekt rozdzielenia pracy i wytwarzania w ramach systemu technologii krzemiennej. Krzemieniarstwo podomowe, narzędzia atypowe wykonywane ad hoc stanowiły pracę w rozumieniu Arendt - a więc były codziennymi czynnościami mającymi znaczenie przede wszystkim w podtrzymaniu egzystencji. Wraz z uproszczeniem technologii została zatracona kulturotwórcza, socjalizująca funkcja czynności pracy. W społecznych procesach strukturyzacji, identyfikacji poszczególnych grup brały udział jedynie wysokiej jakości produkty wytwarzania. Rozdział pracy i wytwarzania ulokował zatem obie formy krzemieniarstwa w przeciwnych miejscach przestrzeni społecznej: pierwszy w sferze prywatnej, drugi publicznej.

Dwa moduły widoczne w późnym krzemieniarstwie możemy opisać przy pomocy rozróżnienia pracy i wytwarzania przedstawionego przez Hannah Arendt. Moduł 
uproszczonego technologicznie krzemieniarstwa podomowego odpowiadałby definicji pracy, zaś produkcja wyspecjalizowanych, wysokojakościowych narzędzi wytwarzaniu. Skoro późne krzemieniarstwo możemy identyfikować ze starożytnym statusem technologii, jej wcześniejsze oblicze charakterystyczne dla społeczności łowiecko-zbierackich nie mieści się w zarysowanej przez Arendt genealogii vita activa. Technologia ta posiada bowiem zarówno cechy pracy, jak i wytwarzania. $\mathrm{W}$ tej postaci technologia pradziejowa jest odwrotnością stanu, z którym mamy do czynienia w nowoczesności - jest wytwarzaniem przez pracę, a nie upracowieniem wytwarzania, jest upojetycznieniem produktu, a nie utowarowieniem poiesis.

Przedstawione filozoficzne koncepcje działań ludzkich opisywały za pomocą różnych pojęć to samo zjawisko - przemiany znaczenia techniki, sztuki, pracy i wytwarzania. Heideggerowskie zestawianie jako podstawowa forma odkrywania, Agambenowskie zespolenie poiesis i praxis czy „upracowienie” wytwarzania u Arendt wydaje się wskazywać na ten sam proces. Punktem wyjściowym do powyższych koncepcji przemian jest przednowoczesność, okres starożytnego arystotelesowskiego klarownego rozdziału pojęć. To co dla Arendt, Agambena i Heideggera jest stanem pierwotnym i początkiem procesu, w kontekście archeologii krzemieniarstwa należy uznać za punkt dojścia. To właśnie w okresie formowania się sfery publicznej i prywatnej, wyraźnego rozdzielenia kategorii pracy i wytwarzania mamy do czynienia z przemianą krzemieniarstwa, która wyznacza zanik pewnej formy społecznego i kulturowego funkcjonowania technologii. Analiza wytwórczości krzemieniarskiej i jej kulturowego znaczenia ukazuje zatem jeszcze wcześniejszą odsłonę relacji człowieka i technologii. W okresie tym wytwórczość krzemieniarska funkcjonuje w ramach jednego systemu technologicznego, a sama czynność wytwarzania narzędzi jest zjawiskiem powszechnym, kształtującym i reprodukującym kulturę.

\section{BIBLIOGRAFIA}

Agamben G.

1999 The Man Without Content. Stanford: Stanford University Press.

Apel J.

2001 Daggers, Knowledge \& Power: The Social Aspects of Flint-dagger Technology in Scandinavia 2350-1500 Cal BC. Uppsala: Uppsala University.

Arendt $\mathrm{H}$.

2010 Kondycja ludzka. Warszawa: Wydawnictwo Aletheia.

Barański J.

2008 Antropologia techniki. Kultura Wspótczesna, 3, s. 22-42.

Dobres M. A.

2000 Technology and social agency. Outlining a Practice Framework for Archaeology. Oxford: Wiley-Blackwell. 
Dusek V.

2011 Wprowadzenie do filozofii techniki. Kraków: Wydawnictwo WAM.

Heidegger M.

1974 Budować, mieszkać, myśleć. Teksty: teoria literatury, krytyka, interpretacja, 6, s. 137-152.

Heidegger M.

1994 Bycie i czas. Warszawa: Wydawnictwo Naukowe PWN.

Heidegger M.

2002a Pytanie o technikę. W: M. Heidegger (red.), Technika i zwrot. Kraków: Wydawnictwo Baran i Suczyński.

Heidegger M.

2002b Zwrot. W: M. Heidegger (red.), Technika i zwrot. Kraków: Wydawnictwo Baran i Suczyński.

Hoły-Łuczaj M.

2013 Heideggerowski Zwrot: jedność bycia i nieantropocentryczna filozofia człowieka. Acta Universitatis Lodziensis Folia Philosophica, 26, s. 95-112.

Kabaciński J.

2010 Przemiany wytwórczości krzemieniarskiej kultur wstęgowych strefy wielkodolinnej Niżu Polskiego. Poznań: Wydawnictwo IAE PAN.

Kabaciński J.

2017 Wytwórczość krzemieniarska w Szczepidle gm. Krzymów, woj. wielkopolskie, stan. 17.

W: P. Makarowicz (red.), Szczepidto. Osada metalurgów kultury mogiłowej nad Warta (s. 451-470). Poznań: Wydawnictwo UAM.

Kogge W.

2010 Heidegger, Dreyfus i pytanie o etykę tego, co techniczne. Fenomenologia, 8, s. 81-91.

Kopacz J.

2012 Koncepcja krzemieniarstwa schyłkowego na przykładzie eneolitu Moraw. Przeglad Archeologiczny, 60, s. 25-47.

Kopacz J., Valde-Nowak P.

1987 Episznurowy przykarpacki krąg kulturowy w świetle materiałów krzemiennych. Archeologia Polski, 31, s. 55-92.

Lech J.

1982/1983 Flint work of the early farmers. Production trends in Central European chipping industries from 4500-1200 b.c. An outline. Acta Archaeologica Carpathica, 22, s. 5-63.

Maliński J.

2016 Technika jako zjawisko historyczne w myśli Karola Marksa, Edmunda Husserla i Martina Heideggera. Filo-Sofija, 32, s. 163-176.

Marks K.

1951

Kapitat. Krytyka ekonomii politycznej (T. 1). Warszawa: Książka i Wiedza.

Masojć M.

2014 Krzemieniarstwo stref rytualnych południowej Skandynawii. Wrocław: Uniwersytet Wrocławski.

Mills C.

2010 Estetyka i fetyszyzm towarowy. W: K. Szadkowski, P. Mościcki (red.), Agamben. Przewodnik Krytyki Politycznej (s. 328-343). Warszawa: Krytyka Polityczna. 
Mościcki P.

2012 Idea potencjalności. Możliwość filozofii wedtug Giorgio Agambena. Warszawa: Instytut Badań Literackich.

Olsen B.

2013 W obronie rzeczy. Archeologia i ontologia przedmiotów. Warszawa: Instytut Badań Literackich.

Pfaffenberg B.

1992 Social Anthropology of Technology. Annual Review of Anthropology, 21, s. 491-516.

Połtowicz-Bobak M.

2013 Wschodnia prowincja magdalenienu. Rzeszów: Uniwersytet Rzeszowski.

Schild R., Królik H., Mościbrodzka J.

1977 Kopalnia krzemienia czekoladowego z przełomu neolitu i epoki brazu w Polanach Koloniach. Wrocław - Warszawa - Kraków - Gdańsk: Zakład Narodowy im. Ossolińskich.

Van Gijn A.

2010 Flint in Focus. Lithic Biographies in the Neolithic and Bronze Age. Leiden: Sidestone Press.

Wąs M.

2005 Technologia krzemieniarstwa kultury janisławickiej. Łódź: Uniwersytet Łódzki.

Wolski D.

2013 Early Bronze Age flint materials from Lesser Poland - their research problems and suggestions for their interpretation. Sprawozdania Archeologiczne, 65, s. 145-193.

\section{PREHISTORIC FLINT WORKING IN PERSPECTIVE OF PHILOSOPHY OF TECHNOLOGY}

\section{S u m m a r y}

The ontological status of lithic technology in stone age was rarely the focus of archaeological studies. The instrumentalist approach or Standard View of Technology, as it is called by Bryan Pfaffenberg, dominates in lithic studies where usually long-term changes in technology are explain by 'natural' factors, the main processes driving this changes are evolution and adaptation. The aim of the paper is to present lithic technology as a social phenomenon, which play significant role in maintaining and reproducing socio-cultural network. Therefore, the radical changes in structure of lithic technology indicate the significant social shift.

The anti-instrumentalist approach to technology can be found in works of Martin Heidegger. The author of 'Being and time' return to ancient understanding of technology (techne) as a part of poiesis. He consider the technology not as a mean to an end but as a beyond-practical human activity, related with revealing the truth. Technology is therefore the process - process of bringing-forth. In modernity this understanding of technology was lost, the things are consider as 'setting-upon'.

The non-practical value of human work explore also Giorgio Agamben, who traces lost in modernity distinguishing of poesis and praxis. The main quality of technology which was reveal the truth was completely overlaid by the understanding it as just act of will. 
The similar problem was raised by Hannah Arendt in her fundamental work "Human condition". She divide human activity on labor, work and action. The distinction between labor and work is especially important for technology studies. The distinction which, as claim Arendt, was ignored by philosophers - the closest concept present Marx as a practical and non-practical value of work. The meet of natural need is the main aim of labor. The products of labor are almost immediately consumed, therefore it is continuous, repeated endless process. This necessity which forced man to labor makes him animal laborans.

The work is attribute of homo faber - is the creating of things, arranging the world makes us human. The work has end in object, product. In the process of working the human creativity can be revealed. Contemporary, as Arendt claim, the clear division between work and labor, and publicprivate as well, is faded. The process of 'laborization' of work has come.

The non-instrumentalist approach presented here has a great impact on interpretation of social meaning of flint technology in prehistory. In the Neolithic, the so-called 'tool-technological revolution' can be observed. The uniformity of technology, which play a significant role in cultural identity since the Palaeolithic to the Early Neolithic period, was gradually replaced by the dichotomical structure of flint technology. One mode in that structure was the high skill products technology, usually of macromorphological tools, bifacially retouched, made by narrow social group of specialist flintknappers, the second mode was socially widely spread extremely simply technology of producing non-diagnostic 'ad hoc' tools. This change show radical shift in social significance of technology. The flint working lost the value as a process of reproducing cultural identity of group, socialization of individuals and maintaining socio-cultural network. Due to the division presented by Arendt, the described change in flint technology indicate the moment when the concept of work and labor as a separate categories appear. The previous form of flint technology existed in prehistory before the shift represent different phase of history of technology. This form of technology combines the attributes of work and labor, where the making of things was socially significance in the process of making itself and in the product as well. 